\title{
Family Violence
}

01 PREVALENCE AND CORRELATES OF INTIMATE PARTNER VIOLENCE AMIONG MALE MILITARY PERSONNEL AND CIVIL SERVANTS IN IBADAN, NIGERIA: A COMPARATIVE STUDY

doi:10.1136/injuryprev-2012-040590q.1

\author{
${ }^{1} \mathrm{~A}$ Adejimi, ${ }^{2} \mathrm{O}$ Fawole, ${ }^{1} \mathrm{O}$ Sekoni, ${ }^{1} \mathrm{M}$ Balogun, ${ }^{1} 0$ Popoola. ${ }^{1}$ Department of \\ Community Medicine, University College Hospital, Ibadan, Nigeria; ${ }^{2}$ Department of \\ Epidemiology and Medical Statistics, University of Ibadan, Nigeria
}

Background The nature of training and work of the military personnel and civil servants may affect their relationships with their intimate partners in different ways.

Objectives The objective of this study was to assess and compare the prevalence and correlates of intimate partner violence (IPV) against female partners among male military personnel and civil servants in Ibadan, South-western Nigeria.

Methods A cross sectional study was carried out using a multi-stage sampling technique. A self administered questionnaire was used in data collection. $\chi^{2}$ test was used to assess association between categorical variables and predictors of perpetration of IPV were determined using logistic regression at level of significance of $5 \%$.

Result A total of 1240 respondents, 631 in the military and 609 in the civil service were interviewed. About $75 \%$ were currently married. The prevalence of perpetration of any form of IPV in the last 12 months of the study was $77.8 \%$ and $66 \%$ among the respondents in the military and civil service, respectively. Significantly higher proportions of respondents in the military had perpetrated various types of IPV except sexual violence. The predictors of perpetrating any form IPV include being a military personnel, childhood exposure to parental IPV, having a negative attitude towards wife beating and use of alcohol. Civil servants were more likely to perpetrate sexual violence against their female partners.

Significance Intimate partner violence was quite prevalence in both groups but significantly more among the military personnel. There is a need for educating these men through multidisciplinary approach and different strategies in the two groups. 